\title{
One-year results of drug-coated balloons for long and occlusive Femoropopliteal artery disease: a single-arm trial
}

\author{
Zhichao Lai ${ }^{\dagger}$, Xin Zhang ${ }^{\dagger}$, Jiang Shao, Kang Li, Lijing Fang, Leyin Xu, Xiaoxi Yu, Jingjing Wang, Xiu Liu,
} Jinsong Lei and Bao Liu* (i)

\begin{abstract}
Background: The performance of drug-coated balloons (DCBs) in femoropopliteal interventions has been proven through randomized trials in short lesions and lesions with relatively low proportion of occlusions. There is limited evidence of DCBs in long or occlusive lesions. This study is to investigate the efficacy of the paclitaxel-coated balloon for treatment of long and occlusive femoropopliteal arterial lesions.

Methods: A single-arm trial including 44 femoropopliteal lesions (chronic total occlusion (CTO) plus $>10 \mathrm{~cm}$ ) treated with DCBs was performed to collect data of average 1-year follow-up. Endpoints contain primary patency, target lesion revascularization (TLR), amelioration of the Rutherford classification, change of ankle brachial index $(\mathrm{ABI})$ and major adverse events.

Results: Technical success is $97.7 \%$ while device success is $100 \%$. Mean lesion length was $186 \pm 86.3 \mathrm{~cm}$. Stent implantation was performed in $13.6 \%$. Cumulative probability of primary patency was $78.8 \% \pm 6.8 \%$ at 1 year while that of freedom from TLR was $91.4 \% \pm 4.9 \%$. Rutherford classification improved from average $3.3 \pm 1.0$ to $2.1 \pm 1.4$ $(p<0.001)$ at follow-up with a $72.7 \%$ amelioration rate. Ankle-branchial index changed from $0.33 \pm 0.40$ to $0.67 \pm 0.37$ $(p=0.002)$. No major adverse event was observed.

Conclusion: These results suggest that it is safe and effective to treat long and totally occlusive femoropopliteal artery disease with DCBs. Further studies are demanded to confirm these results.
\end{abstract}

Keywords: Drug-coated balloon, Femoropopliteal artery, Endovascular intervention

\section{Background}

"Leave nothing behind" strategies are admitted by an increasing number of surgeons. Compared with stents, deployments of balloons can leave a better condition for future possible repeated angioplasty. However, plain old balloon angioplasty seemingly performs not well, especially when used in long and complex lesions $[1,2]$.

To have a better therapeutic effect, drug-coated balloons (DCBs) are an attractive alternative which can inhibit proliferation of tunica intima and restenosis. Many studies of DCBs have proved the superiority on

\footnotetext{
*Correspondence: liubao72@aliyun.com

†Zhichao Lai and Xin Zhang are authors contributed equally to this work and should be considered co-first authors

Department of Vascular Surgery, Peking Union Medical College Hospital, Peking Union Medical College and Chinese Academy of Medical Sciences, Beijing, China
}

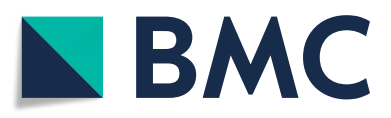

(c) The Author(s). 2020 Open Access This article is distributed under the terms of the Creative Commons Attribution 4.0 International License (http://creativecommons.org/licenses/by/4.0/), which permits unrestricted use, distribution, and reproduction in any medium, provided you give appropriate credit to the original author(s) and the source, provide a link to the Creative Commons license, and indicate if changes were made. The Creative Commons Public Domain Dedication waiver (http://creativecommons.org/publicdomain/zero/1.0/) applies to the data made available in this article, unless otherwise stated.

the efficacy and safety in arteriosclerosis obliterans of low extremities, although recently there are some controversies of long-term safety. But most studies focus on the usage of DCBs in relatively short lesions in femoropopliteal arteries and have a relatively low proportion of chronic total occlusion (CTO) lesions [3-7]. The data of prognosis about long and occlusive lesions is very limited and insufficient $[1$, $2,8]$. Among published article, the result of CTO cohort in IN.PACT Global study by Gunnar Tepe et al. is the only long CTO DCB outcomings, while there are several CTO studies about self-expandable stents [9]. However, long and occlusive lesions are very common challenges in clinical work and tend to have worse outcomings than shorter lesions. It is necessary to have more results about treatment of long and totally occlusive arteriosclerotic lesions with DCBs for future clinical reference. 
With this objective of providing evidence of DCBs in long and occlusive lesions in femoropopliteal arteries, we herein report 1-year follow-up data of patients with CTO femoropopliteal lesions longer than $10 \mathrm{~cm}$. Most past studies with long lesions have proportion of CTO ranging from 40 to $70 \%[1,2,10]$. Although there have been IN.PACT CTO study result reported [9]. It is still the first time to report data from Asian population of long lesions with $100 \%$ proportion of total occlusion.

\section{Patients and methods}

This study was an independent, single-center and singlearm trial of patients with femoropopliteal long and occlusive lesions (excluded stenosis-only lesions) and treated with DCBs, whose objective was to appraise their outcomes in details. The study was retrospectively performed with the DCB data pool of our center. (All patients treated by DCBs were included in this pool and have regular follow-up data. The intervention procedures related to this pool performed by the five operators at our center were standardized before.) All patients have signed informed consent before the procedure. This study was approved by the local institutional review board.

\section{Patients}

Procedures were performed from July, 2016 to March, 2018. Adult patients undergoing treatment of long and occlusive femoropopliteal atherosclerotic lesions with DCBs were screened. Rutherford stages range from 1 to 5 (claudication, rest pain or small ulcer). Angiographic inclusion criteria include lesions in superficial femoral and/or popliteal artery, with minimum lumen diameter being 0 and a total length $\geq 100 \mathrm{~mm}$. Multiple adjacent lesions without angiographic evidence of healthy segments $3 \mathrm{~cm}$ or larger were considered and treated as single lesions. All patients included have at least 1 patent outflow vessel $(<50 \%$ diameter stenosis) before treatment of the femoropopliteal lesions. If there is any lesion in inflow vessels able to be successfully treated before the target femoropopliteal lesion, the patients were deemed eligible. In exclusion criteria, patients who is nonatherosclerotic disease such as aneurysm and vasculitis and patients with any alternative therapies, including atherectomy, excimer laser or cutting balloon during the index procedure, were excluded. Patients who did not adhere to post-procedure dual antiplatelet therapy over 1 month were also excluded.

The capture of follow-up information was at 3 months, 6 months, 1 year and 2 years after the intervention. The mean follow-up time of patients in this study was $388 \pm 217$ days after procedures.

\section{Procedures and devices}

Before procedures, every patient took aspirin $100 \mathrm{mg}$. QD and clopidogrel $75 \mathrm{mg}$. QD for at least 7 days. If patients did not have recent medical history of aspirin or clopidogrel, they would take both for $300 \mathrm{mg} 12 \mathrm{~h}$ before operations. After procedures, patients had to take 100 $\mathrm{mg} /$ day aspirin and $75 \mathrm{mg} /$ day clopidogrel for a minimum of 12 weeks. Most patients are recommended to take atorvastatin $20 \mathrm{mg}$ qd after procedure, no matter how the baselines of low-density lipoprotein cholesterol (LDL-C) are. Besides, if patients take statins before procedure due to hyperlipidemia, it will continue after the procedure.

During the procedures, $75 \mathrm{IU} / \mathrm{kg}$ heparin were administered in each patient after sheath insertion. Most occlusions were passed through intraluminal method while subintimal method was also applied when necessary according to operators' discretion. Pre-treatments before DCBs were pre-dilation $(2 \mathrm{~min})$ with uncoated balloons (0.5 to $1 \mathrm{~mm}$ smaller than reference vessel; visually estimated). DCBs were $1.0 \mathrm{~mm}$ larger than uncoated balloons and inflated only once for $3 \mathrm{~min}$ at 6 to $12 \mathrm{~atm}$ If two DCBs were used for only one lesion, there were at least $5 \mathrm{~mm}$ overlaps between the dilations, since there are $400 \mathrm{~mm}$ lesions and the longest Orchid balloons we used are $300 \mathrm{~mm}$.

If any persistent stenosis (> 30\%) or flow-limiting dissection existed, additional dilations of uncoated balloon would be considered. After repeat dilations, if persistent stenosis or flow-limiting dissection still existed, bailout stents would be deployed.

DCBs used in our center are all Orchid drug-coated balloon by AcoTec company with diameters 4-6 $\mathrm{mm}$ and length 120-300 mm. Provisional stents include Zilver Flex, Protégé Everflex and EverCross stents. All procedures above can be adjusted to some extent under operator's discretion. All operators are chief or associate chief surgeons with sufficient intervention experience. The retrograde access was used twice in 44 patients while subintimal passage method was used once.

\section{Definition and study endpoints}

Device success is defined as the successful access and exact deployment of the device to the target lesion, while technical success is defined as meeting the requirement of device success and the residual stenosis $<30 \%$ in visual estimation after endovascular procedure.

The primary endpoints of this study include primary patency, freedom from clinically driven target lesion revascularization (TLR) and major adverse events (including death of any cause and major target limb amputation). Primary patency is defined as no restenosis proven through clinically driven TLR or evidence of $<50 \%$ residual lumen diameters in the target lesion under computed tomography angiography and peak systolic velocity ratio $>2.4$ under doppler ultrasound examination. Clinically driven TLR is defined as any reintervention of the target lesion because 
of apparent symptoms or imaging results. Secondary endpoints are the change of Rutherford stage (degrees of claudication were classified by meters patients can walk until appearance of symptoms of claudication. Stage 2 ranges 300-500 $\mathrm{m}$ before appearance of claudication.) and the change of ankle brachial index (ABI). Calcification was evaluated as PACSS scale $[11,12]$. Sever degree was defined as two sides of vascular walls have calcification and one of them was longer than $5 \mathrm{~cm}$.

\section{Statistical analysis}

The data were analyzed on the per-protocol population. Descriptive statistics were used to estimate values and changes from baseline as absolute frequencies and percentages for categorical variables and mean \pm standard deviation and medians for continuous variables.

Primary patency and freedom from TLR were estimated by the Kaplan-Meier analyses. Comparison of Rutherford classification and ABI between pre-procedure and followup was calculated through Wilcoxon rank sum test. Cox proportional hazards multivariate regression analysis was used to estimate the influence of potential prognostic factors: sex, lesion length ( $<150 \mathrm{~mm}$ vs. $\geq 150 \mathrm{~mm}$ vs. $\geq 250$ $\mathrm{mm})$ smoking, hypertension, diabetes and calcification. Statistical significance was considered when $p$ values $<0.05$.

\section{Results}

\section{Baseline and procedural characteristics}

Between August 2016 and March 2018, totally 44 patients with 44 femoropopliteal lesions were eligible for this study treated with 48 DCBs. The mean age was $68 \pm 12$ years old and $75.0 \%$ of the population was male. The majority of population had hypertension (70\%) and smoking (57\%) with Rutherford classification 3 or 4 (43 and 30\%, respectively). And half of patients had diabetes. (Table 1).

The mean lesion length was $186 \pm 86.3 \mathrm{~mm}$ with TASC II classification B to D $(43,14$ and $43 \%$, respectively) and $75 \%$ de novo lesions. All included were total occlusion while only $11 \%$ is regarded as moderate or severe calcification (defined as compromising both sides of the arterial wall for at least $5 \mathrm{~cm}$ ). (Table 1).

$\mathrm{DCB} /$ lesion ratio, which is defined as the mean number of DCBs used per lesion, was 1.091 and DCBs were with diameter of $4.59 \pm 0.68 \mathrm{~mm}$ and length of $196.9 \pm 76.9 \mathrm{~mm}$ which is $10 \mathrm{~mm}$ longer than the mean lesion length. 6 bailout stents were used in 44 lesions (13.6\%). The retrograde access was used twice in 44 patients while subintimal passage method was used once. (Table 2).

After procedure, 34 of 44 patients (77.3\%) took atorvastatin $20 \mathrm{mg}$ qd to further decrease LDL-C and restenosis rate.

\section{Efficacy and safety outcomes}

Device success is $100 \%$ while technical success is $97.7 \%$. Cumulative probability of patency by Kaplan-Meier
Table 1 Baseline Clinical Characteristics $(N=44)$

\begin{tabular}{|c|c|}
\hline Age (years) & $68 \pm 12$ \\
\hline Male & $33(75)$ \\
\hline Hypertension & $31(70)$ \\
\hline Hyperlipidemia & $10(22)$ \\
\hline Diabetes & $16(50)$ \\
\hline Prior/Current Smoking & $22(57)$ \\
\hline Renal failure & $1(2)$ \\
\hline Coronary arterial diseases & $12(27)$ \\
\hline Cerebrovascular history & $11(25)$ \\
\hline \multicolumn{2}{|l|}{ Rutherford Class } \\
\hline 1 & $3(7)$ \\
\hline 2 & $4(9)$ \\
\hline 3 & $19(43)$ \\
\hline 4 & $13(30)$ \\
\hline 5 & $5(11)$ \\
\hline 6 & $0(0)$ \\
\hline Lesions number & 44 \\
\hline \multicolumn{2}{|l|}{ Lesion type } \\
\hline De novo & $33(75)$ \\
\hline Restenosis & $11(25)$ \\
\hline \multicolumn{2}{|l|}{ Calcification } \\
\hline None or slight & $39(89)$ \\
\hline Moderate or Severe & $5(11)$ \\
\hline Lesion length(mm) & $186 \pm 86.3$ \\
\hline \multicolumn{2}{|l|}{ Stenosis degree } \\
\hline Slight or Moderate & 0 \\
\hline Severe & 0 \\
\hline Total occlusion & $44(100)$ \\
\hline \multicolumn{2}{|l|}{ TASC $\|$} \\
\hline B & $19(43)$ \\
\hline C & $6(14)$ \\
\hline$D$ & $19(43)$ \\
\hline \multicolumn{2}{|l|}{ BTK outflow } \\
\hline 3 vessels & $26(59)$ \\
\hline 2 vessels & $5(11)$ \\
\hline 1 vessel & $12(27)$ \\
\hline None & $1(2)$ \\
\hline
\end{tabular}

${ }^{\mathrm{a} V a l u e s}$ are $\%(\mathrm{n})$ or mean $\pm \mathrm{SD}$

estimate was $93.2 \% \pm 3.8 \%$ at 3 months, $88.3 \% \pm 4.9 \%$ at 6 months, $78.8 \pm 6.8 \%$ at 1 year and $70.4 \% \pm 8.3 \%$ at 2 years (Fig. 1). The rate of freedom from TLR was 91.4 \pm $4.9 \%$ after 1 to 2 years (Fig. 2).

The mean Rutherford classification of pre-intervention versus follow-up was $3.3 \pm 1.0$ versus $2.1 \pm 1.4$. The amelioration is statistically significant $(p<0.001)$. The amelioration of Rutherford classification was displayed in Fig. 3. 
Table 2 Procedural characteristics $(N=44)$

\begin{tabular}{ll}
\hline Lesions & 44 \\
\hline Technical Success & $97.7 \%(43 / 44)$ \\
Device Success & $100 \%$ \\
DCB/lesion ratio & 1.091 \\
Mean DCB diameter (mm) & $4.59 \pm 0.68$ \\
Mean DCB length (mm) & $196.9 \pm 76.9$ \\
Stenting & $13.6 \%(6 / 44)$ \\
Retrograde Access & $4.54 \%(2 / 44)$ \\
Subintimal Passage Method & $2.27 \%(1 / 44)$ \\
\hline
\end{tabular}

Values are $\%(\mathrm{n})$ or mean \pm SD

Clinical improvement of at least 1 Rutherford classification between pre-intervention and follow-up was in $72.7 \%$ of limbs, while no change in $18.2 \%$ and deterioration in $9.1 \%$. The ABI changed from $0.33 \pm 0.40$ (before procedures) to $0.67 \pm 0.37$ (at 1-year follow-up), statistically significant $(p=0.002)$. The ABI values after procedures but still hospitalized are not included in this study.

No statistically significant association with the primary endpoint was found in the Cox proportional hazards model for sex, smoking, lesion length, TASC II stages, hypertension or diabetes.

As for safety outcomes, there was no procedure- or device-related death or major adverse event through average 1 year.

Main outcomes of this study were listed in Table 3.

\section{Discussion}

In recent years, the studies of DCBs treating atherosclerotic lesions in femoropopliteal arteries have proven favorable results of patency and freedom of TLR. But these studies mainly focused on lesions relatively shorter and stenotic rather than completely occlusive. Many randomized controlled trials (RCTs) have reported results over 3 to 5 -year outcomes with shorter

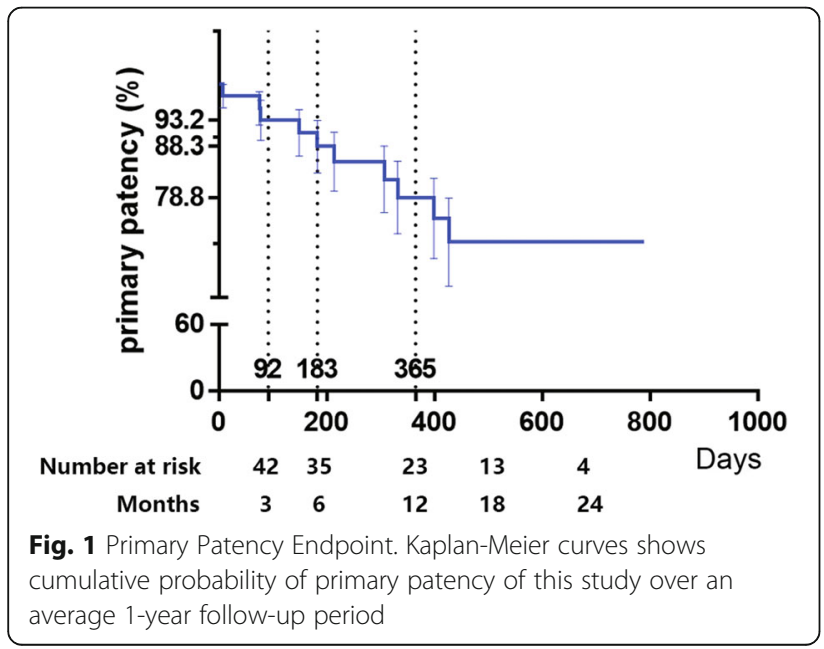

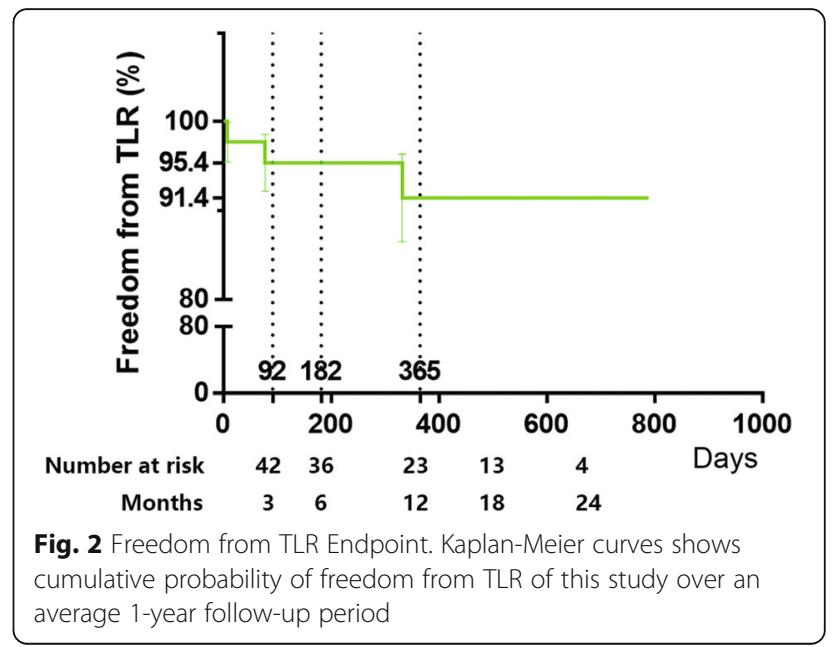

lesions. 1-year TLR rate is from $2.4 \%$ to $12.3 \%$ with mean lesion lengths ranging from $60 \mathrm{~mm}$ to $90 \mathrm{~mm}$. 1year primary patency is from $75.8 \%$ to $87.3 \%$. Even 5year primary patency rate (THUNDER trial) is over $70 \%[10,13,14]$. Nevertheless, long and occlusive lesions are very common and can result in higher possibility of subintimal passage and losing more dose of paclitaxel in passage [15]. For example, if subintimal passage method is used, paclitaxel will contact more with smooth muscle cells other than endothelial cells, which is still controversial and may bring potential differences. (It has been proven in some studies that even smooth muscle cells which do not directly contact the paclitaxel coating can be inhibited effectively in proliferation and migration in vivo [16]. There are also evidences that short-term application of paclitaxel is more significant on smooth cells than on endothelial progenitor cells [17]. However, it is reported no statistical significance found in comparison of intraluminal and subintimal group in long lesions [2].)

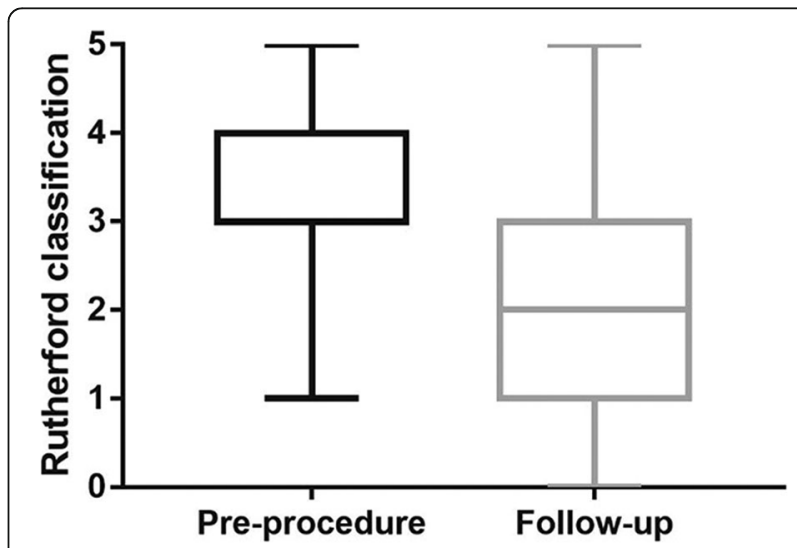

Fig. 3 Functional Results (Rutherford classification). Rutherford classification of pre-procedure and 1-year follow-up was compared 
Table 3 Key Outcomes

\begin{tabular}{llll}
\hline Outcome & $\mathrm{n}(\%)$ & $95 \% \mathrm{Cl}$ & Cumulative Probability \\
\hline Primary Patency & $34(77.3)$ & $64.2-89.2 \%$ & $78.8 \%$ \\
Freedom from TLR & $41(93.2)$ & $85.4-100 \%$ & $91.4 \%$ \\
Amelioration of Rutherford Classification & $32(72.7)$ & $59.0-86.4 \%$ & $/$ \\
& Pre-procedures & Follow-up & $P$ Value \\
Rutherford classification & $3.3 \pm 1.0$ & $2.1 \pm 1.4$ & $<0.001$ \\
Ankle-Branchial Index & $0.33 \pm 0.40$ & $0.67 \pm 0.37$ & 0.002 \\
\hline
\end{tabular}

No independent predictors or major safety endpoints were found

Thus, the results of long and occlusive lesions are very important and needed in clinical work. Until our submission, there are limited articles about long lesions with DCBs. Only the IN.PACT CTO study published in 2019 is focused on long and occlusive lesions and the DCBs [9]. But this is the first study including long and CTO femoropopliteal lesions totally based on Asian population.

In our results, the Kaplan-Meier estimate results of patency rate at average 1-year follow-up is $78.8 \% \pm 6.8 \%$, which is as expected. The IN.PACT CTO study with also $100 \%$ CTO lesions and $22.83 \mathrm{~cm}$ lesion length showed the primary patency is $88.7 \%(n=126)$ [9]. In comparison with other long lesion study, Micari et al. reported 1-year primary patency in femoropopliteal lesions over $150 \mathrm{~mm}(n=101)$ to be $83.2 \%$ while 1 -year primary patency in complex femoropopliteal lesions (lesions over $10 \mathrm{~cm}$ or restenosis) was reported by Schmidt et al. as $79.2 \%[2,8]$. In comparison, 1-year patency rates of shorter lesions with DCBs range mainly from 85 to $90 \%$ (although some results are within 75-85\%) which is higher than that of long-lesion studies to some extent [18-20]. This is probably because long lesions tend to cause higher possibility of subintimal passage and losing more dose of paclitaxel in passage. But since the difference is only $5-10 \%$, the availability of paclitaxel in longer lesions is also satisfactory [15]. There are several studies of self-expandable nitinol stents treating with CTO lesions. The one-year results of primary patency rate are about 72 to $80 \%$. But whether DCBs or traditional devices are better in long and CTO lesions needs further studies [21, 22].

The provisional stent rate in this study is about $13.6 \%$ while that in IN.PACT CTO study is $40.7 \%$ [9]. For further reference, most long but non-CTO study has provisional stent rates ranging from 10.5 to $23.3 \%$ but it could be highest to be $36.6 \%$ for severely calcified lesions [2]. It is possible that operators in our center will try their best and repeat tries to use intra-luminal method other than subintimal which has lower risk of dissection and residual stenosis. In this study, subintimal method is only used once in 44 patients. The other possible reason is that some operators prefer to pre-dilate to have larger luminal diameters while some operators tend to predilate less to decrease the rate of dissection.
Meanwhile, both Fig. 1 and Fig. 2 show that there is almost no restenosis or TLR beyond 450 days after procedures. In some other long-term studies, this shape of curves also exists. For example, in the 2-year long lesion results of Micari et al., the most obvious decrease of primary patency is also between 300 and 400 days after procedures from about 95 to $75 \%$, and the curves after 400 days are also relatively parallel [1]. Also, in the 3year results from Schneider et al., decrease of primary patency is mainly two periods, $0-15$ months and $24-27$ months [10]. However, some studies, such as 2-year complex lesion results by Schmidt et al., show patency rates decreased in a relatively constant speed [2]. It is possible that potential unknown risk factors are more likely to cause restenosis within 450 days and patients without these factors can keep patent over 450 days.

The changes of the Rutherford classification and ABI are favorable, both statistically significant and consistent with expectation. Mean ABI changed from 0.33 to 0.67 and Mean Rutherford classification changed from 3.3 to 2.1 with $72.7 \%$ amelioration rates. In comparison of several similar studies, ABI changes from $0.49-0.63$ to $0.82-$ 0.95 while $\mathrm{ABI}$ changed from 2.4-3.4 to $0.5-2.0$ [2, 8, 23].

The estimate of potential prognostic factors here failed to find any one statistically significant, probably due to the relatively small sample size. But in studies with complex lesions and large sample size, sex, obesity and severe calcification are regard as independent predictors [2]. In those studies, higher restenosis risk of female may relate to smaller lumen diameters while severe calcification means higher risk of recoil and residual stenosis and also interference with the transfer and deposition of the paclitaxel $[24,25]$.

Fortunately, no death or major amputation was found in this study. In most studies of DCBs, there is also no obvious adverse event of DCBs found. Since the only difference between DCBs and plain old balloons is paclitaxel which can decrease thickness of arterial wall, it is theoretically possible to cause ectasia and aneurysm. According to existing literatures, a limited number of aneurysmal dilations after drug-eluting stents or DCBs are only reported in coronary arteries, tibial arteries and femoral-to-below knee popliteal bypass grafts [26, 27]. 
However, in recent 1 year, there has been concern about all-cause death of DCBs. It is hitherto controversial and the Food and Drug Administration of the U.S. recommended to change from DCBs to alternative methods. Thus, more data and further studies about long-term safety are needed to confirm this suspicion.

\section{Limitations}

This study is not randomized or controlled trial and is single-center, which may cause obvious bias. There are patients not attending scheduled follow-up and temporarily lost. Not all doppler ultrasound examinations were performed in our center, which means there is assurance of accuracy. And dropout can be seen to some extent.

\section{Conclusions}

This study focused on long and totally occlusive femoropopliteal arterial atherosclerotic treatment with DCBs. Most lesions (78.8) with DCBs at 1-year follow-up can keep patent, although there were a small number of bailout stents used. Loss of patency mostly happened before the post-operative 450th day. TLR only performed in $6.8 \%$ patients which is much less than the proportion of restenosis. Ameliorations are seen on the Rutherford classifications and ABI, both statistically significant. And no major safety endpoint was observed.

\section{Abbreviations}

ABI: Ankle brachial index; CTO: Chronic total occlusion; DCB: Drug-coated balloon; LDL-C: Low-density lipoprotein cholesterol; TLR: Target lesion revascularization

\section{Acknowledgements}

Not applicable.

\section{Authors' contributions}

ZCL and XZ analyzed the data with statistical methods and wrote this article. $\mathrm{BL}$ supervised the study and finally reviewed the paper. JS and $\mathrm{KL}$ interpreted the data and edited the manuscript. LJF, LYX, XXY, JJW, XL and $J S L$ participated in follow-up work and primarily dealt the data. All authors read and approved this manuscript.

\section{Funding}

Not applicable.

\section{Availability of data and materials}

The datasets generated and analyzed during the current study are available from the corresponding author on reasonable request.

\section{Ethics approval and consent to participate}

The Institutional Review Board of Peking Union Medical College Hospital approved this study. Written informed consents were signed by all patients.

\section{Consent for publication}

Not Applicable.

\section{Competing interests}

The authors declare that they have no competing interests.
Received: 16 November 2019 Accepted: 22 January 2020

Published online: 06 February 2020

\section{References}

1. Micari A, Nerla R, Vadalà G, Castriota F, Grattoni C, Liso A, et al. 2-year results of paclitaxel-coated balloons for long femoropopliteal artery disease: evidence from the SFA-long study. J Am Coll Cardiol Intv. 2017;10(7):728-34.

2. Schmidt A, Piorkowski M, Görner H, Steiner S, Bausback Y, Scheinert S, et al. Drug-coated balloons for complex femoropopliteal lesions: 2-year results of a real-world registry. J Am Coll Cardiol Intv. 2016;9(7):715-24.

3. Katsanos K, Spiliopoulos S, Paraskevopoulos I, Diamantopoulos A, Karnabatidis D. Systematic review and meta-analysis of randomized controlled trials of paclitaxel-coated balloon angioplasty in the femoropopliteal arteries: role of paclitaxel dose and bioavailability. J Endovasc Ther. 2016;23(2):356-70.

4. Tepe G, Laird J, Schneider P, Brodmann M, Krishnan P, Micari A, et al. Drugcoated balloon versus standard percutaneous Transluminal angioplasty for the treatment of superficial femoral and popliteal peripheral artery DiseaseCLINICAL PERSPECTIVE: 12-month results from the IN. PACT SFA Randomized Trial. Circulation. 2015;131(5):495-502.

5. Rosenfield K, Jaff MR, White CJ, Rocha-Singh K, Mena-Hurtado C, Metzger DC, et al. Trial of a paclitaxel-coated balloon for femoropopliteal artery disease. N Engl J Med. 2015;373(2):145-53.

6. Micari A, Cioppa A, Vadalà G, Castriota F, Liso A, Marchese A, et al. Clinical evaluation of a paclitaxel-eluting balloon for treatment of femoropopliteal arterial disease: 12-month results from a multicenter Italian registry. J Am Coll Cardiol Intv. 2012;5(3):331-8.

7. Zeller T, Rastan A, Macharzina R, Tepe G, Kaspar M, Chavarria J, et al. Drugcoated balloons vs. drug-eluting stents for treatment of long femoropopliteal lesions. J Endovasc Ther. 2014;21(3):359-68.

8. Micari A, Vadalà G, Castriota F, Liso A, Grattoni C, Russo P, et al. 1-year results of paclitaxel-coated balloons for long femoropopliteal artery disease: evidence from the SFA-long study. J Am Coll Cardiol Intv. 2016;9(9):950-6.

9. Tepe $\mathrm{G}$, et al. Drug-coated balloon treatment for femoropopliteal artery disease: the chronic total occlusion cohort in the IN. PACT global study. J Am Coll Cardiol Intv. 2019;12(5):484-93.

10. Schneider PA, Laird JR, Tepe G, Brodmann M, Zeller T, Scheinert D, et al. Treatment effect of drug-coated balloons is durable to 3 years in the Femoropopliteal arteries: long-term results of the IN.PACT SFA randomized trial. Circ Cardiovasc Interv. 2018;11(1):e005891.

11. Rocha-Singh KJ, Zeller T, Jaff MR. Peripheral arterial calcification: prevalence, mechanism, detection, and clinical implications. Catheter Cardiovasc Interv. 2014;83(6):E212-20.

12. Okuno S, et al. Impact of calcification on clinical outcomes after endovascular therapy for superficial femoral artery disease: assessment using the peripheral artery calcification scoring system. J Endovasc Ther. 2016;23(5):731-7.

13. Tepe G, Schnorr B, Albrecht T, Brechtel K, Claussen CD, Scheller B, et al. Angioplasty of femoral-popliteal arteries with drug-coated balloons: 5-year follow-up of the THUNDER trial. J Am Coll Cardiol Intv. 2015;8(1):102-8.

14. Herten M, Torsello GB, Schönefeld E, Stahlhoff S. Critical appraisal of paclitaxel balloon angioplasty for femoral-popliteal arterial disease. Vasc Health Risk Manag. 2016;12:341-56.

15. Granada JF. Drug-Coated Balloons for In-Stent Restenosis: A Fierce Fight for a "Me-Too" Space; 2018. p. 2378-80.

16. Axel DI, Kunert W, Göggelmann C, Oberhoff M, Herdeg C, Küttner A, et al. Paclitaxel inhibits arterial smooth muscle cell proliferation and migration in vitro and in vivo using local drug delivery. Circulation. 1997;96(2):636.

17. Clever YP, Cremers B, Krauss B, Böhm M, Speck U, Laufs U, et al. Paclitaxel and sirolimus differentially affect growth and motility of endothelial progenitor cells and coronary artery smooth muscle cells. Eurolntervention. 2011;7:K32-42.

18. Laird JR, Schneider PA, Tepe G, Brodmann M, Zeller T, Metzger C, et al. Durability of treatment effect using a drug-coated balloon for Femoropopliteal lesions. J Am Coll Cardiol. 2015;66(21):2329-38.

19. Byrne RA, Joner M, Alfonso F, Kastrati A. Drug-coated balloon therapy in coronary and peripheral artery disease. Nat Rev Cardiol. 2014;11(1):13-23.

20. Schroeder H, Meyer DR, Lux B, Ruecker F, Martorana M, Duda S, et al. Twoyear results of a low-dose drug-coated balloon for revascularization of the femoropopliteal artery: outcomes from the ILLUMENATE first-in-human study. Catheter Cardiovasc Interv. 2015;86(2):278-86. 
21. Farraj N, Srivastava A, Pershad A. One-year outcomes for recanalization of long superficial femoral artery chronic total occlusions with the Viabahn stent graft. J Invasive Cardiol. 2009;21 (6):278-81.

22. Matsumi J, et al. Long-term outcomes of self-expandable Nitinol stent implantation with intraluminal angioplasty to treat chronic Total occlusion in the superficial femoral artery (TransAtlantic inter-society consensus type D lesions). J Invasive Cardiol. 2016;28(2):58-64.

23. Jia X, Zhang J, Zhuang B, Fu W, Wu D, Wang F, et al. Acotec drug-coated balloon catheter. J Am Coll Cardiol Intv. 2016;9(18):1941-9.

24. Werk M, Albrecht T, Meyer DR, Ahmed MN, Behne A, Dietz U, et al. Paclitaxel-coated balloons reduce restenosis after Femoro-popliteal angioplasty evidence from the randomized PACIFIER trial. Circ Cardiovasc Interv. 2012;5(6):831-40.

25. Fanelli F, Cannavale A. Calcium burden assessment and impact on drugeluting balloons in peripheral arterial disease. Cardiovasc Interv Radiol. 2014; 37(4):898-907.

26. Diamantopoulos A, Gupta Y, Zayed H, Katsanos K. Paclitaxel-coated balloons and aneurysm formation in peripheral vessels. J Vasc Surg. 2014;62(5):1320-2.

27. Vassilev $D$, Hazan M, Dean L. Aneurysm formation after drug-eluting balloon treatment of drug-eluting in-stent restenosis: first case report. Catheter Cardiovasc Interv. 2012;80(7):1223-6.

\section{Publisher's Note}

Springer Nature remains neutral with regard to jurisdictional claims in published maps and institutional affiliations.

Ready to submit your research? Choose BMC and benefit from:

- fast, convenient online submission

- thorough peer review by experienced researchers in your field

- rapid publication on acceptance

- support for research data, including large and complex data types

- gold Open Access which fosters wider collaboration and increased citations

- maximum visibility for your research: over $100 \mathrm{M}$ website views per year

At BMC, research is always in progress.

Learn more biomedcentral.com/submissions 